International Journal of Linguistics, Literature and Translation

ISSN: 2617-0299 (Online); ISSN: 2708-0099 (Print)

DOI: $10.32996 / \mathrm{ijlt}$

Journal Homepage: www.al-kindipublisher.com/index.php/ijllt

\title{
The Influence of Linguistic Insecurity on Thai EFL Teachers' Teaching Performance
}

\author{
Palatee Jantri' 9 (D) $\triangle$ and Pilanut Phusawisot ${ }^{2}$ 8(D) \\ ${ }^{12}$ Postgraduate Student, Department of Western Languages and Linguistics, Faculty of Humanities and Social Sciences, \\ Mahasarakham University, Thailand
}

$\triangle$ Corresponding Author: Palatee Jantri, E-mail: toeyiab@gmail.com

\author{
ARTICLE INFORMATION \\ Received: July 13, 2021 \\ Accepted: August 10, 2021 \\ Volume: 4 \\ Issue: 8 \\ DOI: $10.32996 /$ ijllt.2021.4.8.6
}

\section{KEYWORDS}

Linguistic Insecurity,

Teaching Performance,

EFL Teachers

\section{ABSTRACT}

Using a case study approach, this study focused on teachers' linguistic insecurity. The purpose of this study was to investigate the influences of Thai EFL teachers' linguistic insecurity on their teaching performance. The data were obtained from classroom observation and semi-structured interviews. Using a purposive sampling, the participants were two Thai EFL teachers who were in-service teachers at a public secondary school in the northeastern part of Thailand. The study was conducted in the second semester of the 2020 academic year. Data were analyzed by using content analysis to identify themes. The results of the study indicated that the participants perceived that linguistic insecurity influenced their teaching performance in three aspects: lack of confidence about English knowledge, poor performance in English language teaching, and negative self-concept toward their English language ability. The discussion of findings, pedagogical implications, and recommendations for further investigations were also discussed.

\section{Introduction}

Due to the growing number of English language users worldwide, English has become the communication medium used by many people from different parts of the world. This has led to a steady increase in the number of English language teachers and learners. Moreover, the proportion of non-native English speakers to natives has been steadily increasing with the rapid expansion of the use of the English language as a lingua franca (Arva \& Medgyes, 2000; Crystal, 2003; Graddol, 1999), and nonnative speakers have become the majority of English language teachers globally (Canagarajah, 2005; Moussu \& Llurda, 2008). Indeed, in the field of English language teaching (ELT), an increasing number of teachers are not native speakers of English (Muam, 2002); Braine (2010) mentioned that $80 \%$ of the English teachers worldwide are non-native speakers of the language. This trend has encouraged researchers to approach issues associated with non-native English-speaking teachers (Selvi, 2014).

Despite the increasing number of non-native English-speaking teachers, there is still a global bias against non-native English speakers, especially in ELT. In addition, some non-native speakers of a language face challenges in terms of socio-cultural and racial socioeconomic differences, including feelings of anxiety, self-consciousness, and lack of confidence. These factors can impact non-native speakers' self-perception, and a negative self-perception causes linguistic insecurity. In the case of language teachers, lack of self-confidence and linguistic insecurity can hinder the process of teaching and learning.

Many scholars in different contexts have reviewed the term "linguistic insecurity". Linguistic insecurity was first mentioned in 1972 by an American linguist, William Labov. Labov defined linguistic insecurity as the speaker's confidence in the perceived correctness of their use of a language. Later, Bucci and Baxter (1984) described linguistic insecurity as the speaker's negative selfperception concerning their speech variety. This might occur when the speaker compares the characteristics of their speech, in terms of phonetic and syntactic characteristics, with the expected "accurate" form of the spoken language. Thus, the concept of correctness and inferiority have been identified as the core elements of linguistic insecurity. Baron (1976) also described linguistic insecurity as the feeling of many non-native English speakers who recognize their errors. Meyerhoff (2006) stated that linguistic insecurity is speakers' feeling with their language variety as inferior or inadequate. Finally, Hall, Smith, and Wicaksono

K C C AL-KINDI CENTER

$\mathbf{R}$ D FEVELOPMENT

Your gateway to world-class research

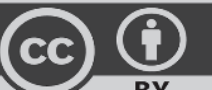

Published by Al-Kindi Center for Research and Development, London, United Kingdom. Copyright (c) the author(s). This open access article is distributed under a Creative Commons Attribution (CC-BY) 4.0 license 
(2011) explained the concept of linguistic insecurity as the speaker's belief that their lack of language variety in terms of speech and writing makes them somehow inferior. Therefore, despite some differences in the core elements of linguistic insecurity, most scholars agree that the term "linguistic insecurity" represents the concept of negative self-perceptions of an individual's language and their use of the language. In other words, linguistic insecurity is situational anxiety and self-consciousness felt when using one's language. This is different from foreign language anxiety, where the fuel of the anxiety is the acquisition of the language.

Several studies have been conducted on linguistic insecurity in different contexts (Labov, 1966; Owens \& Baker, 1984; Daftari, 2016). For example, in the social context, Labov (1966) assessed the linguistic insecurity of the lower middle class in 1960s New York City. It was found that lower-middle-class members were more likely to experience linguistic insecurity. Some significant causes of this linguistic insecurity were a broad range of stylistic variations, fluctuation in given stylistic contexts, conscious attempts at correctness, and negative attitudes towards their native speech pattern. In a gender context, Owens and Baker (1984) used the CILI (Canadian Index of Linguistic Insecurity) and ILI (Index of Linguistic Insecurity) to assess the linguistic insecurity of male and female participants. The findings showed that women's linguistic insecurity was higher than men's in ILI and the CILI.

In an educational context, Daftari and Travil (2017) examine non-native English-speaking teachers' linguistic insecurity and investigate its influence on learners' productive skills by using SPSS software. The results indicated that Turkish EFL teachers experienced a low level of linguistic insecurity in their classrooms. Lee et al. (2017) researched by focusing on non-native Englishspeaking teachers' anxieties and insecurities. They examine non-native English-speaking teachers' self-perceived English proficiency levels, anxieties, or insecurities due to the participants' perceptions of communicative limitations and their strategies to reduce those anxieties or inferiority feelings. The results reveal that the participants possessed positive self-perceptions about themselves. They also perceived their strengths and weaknesses as non-native English-speaking teachers and believed they could teach English as efficiently as native English-speaking teachers. In another study, Foo and Tan (2018) researched by focusing on the two concepts which have never been discussed in conjunction: the relationship between linguistic insecurity and linguistic ownership. This paper set a condition to test for the presence of linguistic insecurity and the exercise of linguistic ownership in 287 Singaporeans through a survey examining their use of English and their perceptions of other speakers in the Singapore English-speaking community and Singapore English itself. The results reveal that Singaporeans are linguistically insecure yet exercise full ownership of the English language.

However, there is still a gap in the research on non-native English-speaking teachers' linguistic insecurity from English language teaching (ELT). Several studies have been conducted on linguistic insecurity in countries where English is used as a first or second language. However, these studies have largely employed quantitative methods. Very little research has been carried out on linguistic insecurity experienced by English as a foreign language (EFL) teachers and how it influences their teaching performance. Moreover, in the Thai context, qualitative research is rarely used to study linguistic insecurity. Thus, the present study adopted a case study approach to investigate Thai EFL teachers' linguistic insecurity and how linguistic insecurity influences their language performance. The present study fills an important gap in the current literature by focusing on nonnative English-speaking teachers' insecurities.

The present study focused on teachers' linguistic insecurity. Specifically, it aimed to investigate the influence of Thai EFL teachers' linguistic insecurity on their teaching performance. The following research question is formulated to guide the study:

- How does the Thai EFL participants' perceived linguistic insecurity influence their teaching performances?

\section{Literature Review}

\subsection{Linguistic Insecurity}

The main focus of the present research is to investigate the influences of linguistic insecurity on Thai EFL teachers' teaching performance. Therefore, the following section reviews the study conducted in linguistic insecurity, including definitions, sources, and common effects.

\section{Definition of Linguistic Insecurity}

Linguistic insecurity is a sense of unease, discomfort, or anxiety experienced when using or attempting to use one's first language or second language due to various environmental, perceptional, interpersonal, organizational, cultural, and social factors. In other words, linguistic insecurity refers to feelings of anxiety, self-consciousness, or lack of confidence in the speaker's language use. This kind of anxiety comes from a speaker's belief that their use of language does not meet the standard of the native language. Labov (1972) describes linguistic insecurity as demonstrated by members of the lower-middle-class in their wider range of stylistic variation in speech, their fluctuation within a given stylistic context, their constant striving for correctness, and their strongly negative attitudes toward their native speech pattern. Then, Bucci and Baxter (1984) describe linguistic insecurity as the speakers' negative perception of speech variety. It might happen when the speakers compare their phonetic and syntactic characteristics of speech with an expected accurate form of the spoken language. This feeling of insecurity tends to 
be consistent with a perception that grammar, accent, and choice of words fail to align with standardized language norms, leading to the fear of being discredited and deprived of identity as members of the community or society in which these norms circulate (Bretegnier \& Ledegen, 2002). In other words, linguistic insecurity is based on the perception of a lack of correctness regarding one's speech rather than any objective deficiencies in a particular language variety.

As mentioned above, it can be concluded that the term "linguistic insecurity" describes as the speakers' negative self-perception concerning the speech variety. Moreover, in the present study, linguistic insecurity also refers to the feeling of having inadequate language skills, not being good enough, and lacking confidence experienced by Thai EFL teachers.

\section{Sources of Linguistic Insecurity}

The research in linguistic insecurity was conducted, focusing on the causes and manifestations of this phenomenon. However, the fact is that linguistic insecurity remains a complex and multiform reality, making it difficult to assess this phenomenon. Linguistic insecurity has situationally provoked the feeling of inadequacy regarding personal performance in specific contexts. This insecurity can lead to stylistic and phonetic shifts away from an affected speaker's default speech variety; these shifts may be performed consciously on the speaker's part or unconsciously by putting an effort to conform to the context-appropriate style of speech (Bucci and Baxter, 1984). It is related to the perception of the styles of speech in the community, and according to Labov (1966), it may be based on socioeconomic class and gender. Baron (1976), a linguist and cultural historian, stated that there are two possible sources of linguistic insecurity: (1) the notion of more or less prestigious dialects and (2) the exaggerated idea of correctness in a language. It might be additionally suggested that this American linguistic insecurity comes historically from a third source, a feeling of cultural inferiority (or insecurity). A particular case is a belief that somehow American English is worse or less proper than British English. Indeed, one can frequently hear comments made by Americans indicating that they regard British English as a superior form of English.

Although linguistic insecurity might be perceived as somewhat inadequate to refer to a procedure of evaluating linguistic prestige, it would be justified by its consequences among speakers. Thus, hypercorrection, nervousness, self-correction, doubt, erroneous perception of one's speech pattern or an essential fluctuation between different speech styles have been associating with insecure individuals' language usage (Labov, 2006).

\section{Linguistic Insecurity of Non-native English-speaking Teachers}

Linguistic insecurity of language speakers is often correlated to pronunciation. In the case of non-native teachers, it is referred to as the feeling of insecurity when teaching grammar, vocabulary, and pronunciation. Individuals may have preferences about teaching particular skills or components. Still, they seem to feel insecure when teaching special skills or elements if they feel linguistically insecure about that part. The emphasis on native-speaking teachers' correctness, whatever its source, seems to have the effect of arousing feelings of linguistic insecurity among non-native-speaking teachers. For non-native teachers of English, it means their acceptance of the negative stereotyping of their English by the native-speaking community, regardless of the kind of English spoken between its native speakers, is not appropriate to most non-native speaking communities (Jenkins, 2004).

According to Gagliardi and Maley (2010), almost $98 \%$ of Italian foreign language teachers are native Italian speakers who often describe their linguistic insecurity in the foreign language they teach as a significant professional weakness affecting their professional identity development. As non-natives, they experience the uneasiness of language teaching associated with a culture that they rarely expose. It is not only the case with Italian foreign language teachers, but also with teachers in other countries. Most of the foreign language teachers in each country seem to be native speakers of that country, and the feeling of linguistic insecurity is common to all non-native teachers of foreign languages. Medgyes (1992) points out that NNESTs usually feel insecure about using language under their responsibility to teach. Due to this feeling, they are inclined to adopt two kinds of attitudes: pessimistic or aggressive. Both feelings are limit and can disturb the teaching process. To recognize and investigate the negative consequences of feeling a high level of linguistic insecurity was the researcher's initial motivation to conduct this present study.

\section{Most Common Effects of Linguistic Insecurity}

Linguistic insecurity can have a negative impact on the individual speaker's confidence in using the language. For example, it can lead to a feeling that the individual's use of the language is not consistent with established norms and principles. Another negative impact of linguistic insecurity is that it can discourage the use of a language, which can lead to an erosion of capacities, a loss of confidence in one's mastery of the language, and even a loss of one's sense of freedom to use it. While research has revealed that linguistic insecurity influences teachers' instruction and decisions to approach certain kinds of professional development (e.g., Wernicke, 2017), it also reproduces traditional monolingual models of language learning. It uses, notably for students who may themselves be aspiring to become English teachers in the future. 


\subsection{Teacher Teaching Performance}

Teacher teaching performance is another factor focused on in this present study. It refers to teachers' actions regarding how teachers produce and convey specific language points such as vocabulary, grammar, and pronunciation when speaking. Since the assessment of teacher teaching performance is measurable by looking at teacher's competencies. Thus, this section was also gathering the literature review of teacher's competencies instead. Competencies focus on what and how the teachers must do to engage in the essential elements of teaching. It is also a combination of knowledge, ability, and experience that perfectly allows individuals to perform a task. The ability of a person to reveal a system related to the function in achieving performance goals is also known as competencies (Boyatzis, 1982). Competence is often called a group of related knowledge skills and attitudes that affect one's duties, are closely related to job performance, and are measured according to certain standards.

Based on Iceberg Competency Model (Spencer \& Spencer, 1993), the elements of competency are knowledge, skills, attitudes, personalities, and values. The three main things that need to be considered in determining the learning outcomes to be achieved by students are knowledge (cognitive), skills (psychomotor domain), and attitude (affective domain). The components of competence assessment are knowledge, attitudes, and skills (Carraciao \& Englander, 2004). Iceberg's model said knowledge and skills developed and are more easily identified than personality attitude, which is difficult to identify, modify, and mold (Mestry, \& Grobler, 2004). However, the attitude of personality is the essential factor. It should be taken into consideration before determining the level of competence of a teacher than having the knowledge and skills needed in options education. In this study, Iceberg's model was employed as teachers' competency to assess teacher teaching performance. Therefore, it can be concluded that teacher competence in teaching practice is a combination of knowledge, skills, and attitudes in effectively carrying out teaching practice.

\section{Methodology}

The present study aimed to explore Thai EFL teachers' linguistic insecurity and its influence on teachers' teaching performances. A case study approach was used to understand Thai EFL teachers' linguistic insecurity in the Thai EFL context. It starts with a detailed description of the participants and the setting. This chapter also presents the method used in this study, including research instruments, data collection procedures, and data analysis. Finally, ethical considerations are discussed.

\subsection{Participants and Setting}

\section{Participants}

The participants were two Thai EFL teachers who work as English teachers. These two Thai EFL teachers are selected because they are likely to generate valuable data for this research. In addition, both participants are in-service teachers with more than five years of EFL teaching experience. All the English teachers from the selected secondary school in northeastern Thailand were asked to answer the Index of Linguistic Insecurity (ILI) questionnaires. In order to have a deeper understanding of the teachers' linguistic insecurity, two high-linguistic insecurity teachers were selected as the participants according to their scores in the questionnaires. The two Thai EFL teachers identify themselves as Thai EFL teachers who do not feel confident when teaching, feel stressed when teaching vocabulary, grammatical, and pronunciation sections, and believe they need to improve their English.

These two Thai EFL teachers (Teacher A and Teacher B) were the best fit to participate in the study for three reasons: (1) the participants teach at the secondary level, (2) the participants got high scores in the linguistic insecurity questionnaires, and (3) their willingness to contribute to the research. In addition, the two teachers were both qualified, with more than five years of EFL teaching experience. Therefore, the participants were asked to voice their opinions about how Thai EFL teachers' linguistic insecurity influences their teaching performances. Brief information of the participants is provided in detail in the following sections.

Teacher A: The first participant, "Teacher A", is a female teacher. She has over eight years of EFL teaching experience. Teacher A held Bachelor's degrees in English and Master's degrees in Education. Now, she is teaching at the uppersecondary level. Her main subjects are English for Communication and English Listening and Speaking.

Teacher B: The second participant, "Teacher B", is also a female teacher with nine years of experience in teaching EFL. Teacher B held Bachelor's degree in Education. Teacher B is teaching for twelve years at a selected secondary school in the northeastern part of Thailand. Her main subjects are General English and English for Specific Purpose for the uppersecondary level.

\section{Setting}

The researcher used a purposive sampling to select the school. The present study was conducted in a secondary school in the northeastern part of Thailand. Qualitative research was purposively conducted in natural settings in order to ensure that as little as possible of the phenomenon to be studied is altered (Streubert \& Carpenter, 1999). This school is a well-known secondary school in the northeastern region of Thailand. The school was founded 50 years ago. It is a large school with approximately 4,000 students as of the year 2020. There are various kinds of programs to foster students' expertise. At the time of the study, there 
were 15 classrooms for the lower-secondary level, including the Enrichment Science Classroom (ESC), Intensive English Program (IEP), and regular classrooms. The upper-secondary level consisted of 15 classrooms, including the Enrichment Program of Science, Mathematics, Technology and Environment (SMTE), Mathematics and Science program, Mathematics and English program, and English and Chinese program.

The total number of teachers in this school is around 250. The study was conducted in the foreign language department of this secondary school. There were 30 teachers in foreign language departments teaching Chinese and English. Amongst the 24 English teachers were asked to answer the index of linguistic insecurity questionnaire.

\subsection{Research Instruments}

In order to address answers to the research question, the following two research instruments were used: classroom observation and semi-structured interviews. These instruments are described in detail in the following sections.

\section{Classroom Observations}

Classroom observations were used to investigate Thai EFL teachers' perceptions of their linguistic insecurity while teaching in a classroom. The observations were carried out over four weeks. Each participant was observed three times. Field-note-taking was used during the observations. Specifically, this field-note-taking included notes about the teachers' use of English in the classroom and how linguistic insecurity influences teachers' teaching performances. The duration of the recording for each session was 50 minutes. After each teaching observation, the researcher conducted an informal 5-10-minutes interview with the participants based on their classroom activities in order to understand their linguistic insecurity.

\section{Semi-structured Interview}

After observing both the participants, the researcher conducted semi-structured interviews. Semi-structured interviews were conducted with the two participants to collect in-depth qualitative data. According to Cohen and Manion (1994), interviews are a helpful tool to understand the factors governing behavior. Specifically, the semi-structured interviews were used to gain additional data on the participants' perceptions of their linguistic insecurity that were not reflected in the classroom observations and journals. The interviews were tape-recorded and later analyzed by the researcher. Both participants were separately interviewed by the researcher in the Thai language. However, the researcher often followed up the semi-structured questions with questions such as, "Why?" and "Can you tell me more?" This was the researcher's way to get a deeper meaning and richer understanding of the participant's experiences. Interviews were transcribed within a couple of days of occurrence. After that, participants were able to review, verify and modify their comments. Finally, the scripts were sent to both participants for member checking. Subsequently, the transcripts were read twice by the researchers and categorized into themes. Each theme was then supported by direct verbatim to provide an audit trail.

\subsection{Data Collection Procedure}

All of the data for the present study were collected during the 2020 academic year. After obtaining permission from the public secondary school, the classroom observations began. In classroom observation, the researcher observed the teachers' use of English in their speaking classes. After classroom observations, semi-structured interviews were conducted. The questions in the semi-structured interviews were based on the issues identified during the classroom observation and were structured in such a way as to understand the teachers' linguistic insecurity better. The interviews were conducted in Thai and lasted between 30 and 60 minutes. The interviews were recorded - with the consent of the participants - and then transcribed into themes.

\subsection{Data Analysis}

After conducting the semi-structured interviews, the recorded interviews were transcribed and coded to understand the participants' perspectives. Finally, the transcripts were analyzed using content analysis. The coding procedure began with careful reading of the data in order to identify recurring themes and sub-themes. After coding and transcribing, the data were categorized into themes for further content analysis.

The quality of qualitative research was established by trustworthiness. This study maintained trustworthiness via member checking. Johnson and Christensen (2008) identify that research has to have data, findings, and interpretation accuracy or credibility through some strategies. Thus, to ensure the trustworthiness of the qualitative data, this study applied the triangulation method. As Cresswell (2008, p.266) stated, "Qualitative data requires triangulating among different data sources to enhance the study's accuracy. Triangulation is the process of corroborating evidence from different individuals (e.g., principal and a student), type of data (e.g., observation fields notes and interviews), or method of data collection (e.g., documents and interview) in descriptions and themes in qualitative research." The following technique was used to ensure the trustworthiness and credibility of data collection and interpretation: member checking. This technique involved some participants in the research, helping to check the accuracy of the data and findings (Creswell, 2012). 


\section{Results and Discussion 4.1 Results of Research}

In order to elicit a more transparent understanding regarding the participants' linguistic insecurity, classroom observation and semi-structured interviews were conducted alongside recording in the researcher's note-taking. In the semi-structured interviews, the participants reported experiencing insecurities when using English in classrooms as well as feelings of uneasiness and worry when using English in class.

\section{Research Question: $\quad$ How does the Thai EFL participants' perceived linguistic insecurity} influence their teaching performances?

The purpose of this research aims to investigate the influence of Thai EFL teachers' linguistic insecurity on their teaching performances. In order to answer this research question posed in this study, classroom observation and semi-structured interviews were conducted to investigate the influences of linguistic insecurity on Thai EFL teachers' teaching performance. During the semi-structured interviews and classroom observation, the participants revealed the influences of linguistic insecurity that obstruct their teaching performance. After the data were collected and analyzed to identify the influence of linguistic insecurity on Thai EFL teachers' teaching performance, three primary themes were identified: 1) lack of confidence about English knowledge, 2) poor performance of English language teaching, and 3) negative self-concept. These emerging themes demonstrated the main influences of linguistic insecurity on Thai EFL teachers' teaching performance.

\section{Lack of Confidence about English Knowledge}

Lack of confidence about English knowledge when teaching and using English was stated as the primary influence of linguistic insecurity, which affected teaching performance. During the data collection process, the participants reported feeling nervous and overwhelmed when communicating in English due to their lack of confidence about English knowledge. They mentioned that this lack of confidence obstructs their teaching performance. Both participants reported that they are not confident in their language knowledge. The participants also stated that a lack of confidence in their English knowledge is the leading cause of their decreased teaching performance. This lack of self-confidence threatens the teachers with the belief that they are not good English speakers.

To understand why both teachers lack confidence in English knowledge, the data were gained from classroom observations and semi-structured interviews. Below are the sections from the interviews that support the themes of anxiety or a sense of insecurity due to their lack of confidence about English knowledge:

"I was not confident, and I felt insecure. Especially in an advanced class, a few students had high proficiency in speaking English. I felt so nervous when I could not think of appropriate words to answer their unexpected questions, although I thought I had prepared for the class well. The problem that I am facing, in particular, is that I know only a little vocabulary. I remembered well when I was going blank in front of my students because I cannot answer my students' questions in English. That situation left me confused and worried. Sometimes, I get very anxious when not prepared to speak, and I feel nervous when I misuse words. Actually, I know what I am going to say, but I cannot think of the words. Due to linguistic insecurity, I often like to use simple words to explain the lesson. Almost every time I teach grammar sessions, I always had the feeling of linguistic insecurity before and during the class. I am not sure about my grammar knowledge, even if I have taught and learned grammar more than 100 times. I can remember a few and simple pieces of vocabulary. I skipped some parts that I am unsure about and assigned my students to research and do the presentation about this topic instead of teaching them."

(Teacher A)

"I sometimes think that my English knowledge is not good enough. And that may influence me, making me unconfident when I talk to my students. I felt like this insecurity hampered my teaching performance to produce output smoothly. When I teach grammar, I always assign my students to read about the rule or concepts of the lesson before coming to class. It can ease my feeling of anxiety. I tend to avoid teaching some difficult parts. It also reduces words production. I am not sure if the words, sentences, and pronunciation I used in the class are correct. I always had a sense of linguistic insecurity in my mind. Sometimes, while teaching, I feel uncertain about the correct expressions and grammar to use. I sometimes could not give the right meaning immediately. I have to search on a dictionary application on my cellphone. I felt rather uncomfortable when I did not know the meaning of a word in the textbook. Moreover, I often said some words of hesitation like umm. In the first year of teaching, I felt very self-conscious about speaking English in front of students, especially in the special English class. I was afraid that students would notice when I am mispronouncing or using the wrong grammar. Moreover, I realize that I often use the wrong grammatical structure."

(Teacher B)

According to the findings, linguistic insecurity influences teachers' lack of confidence about English knowledge while teaching English. The finding presents a relatively common experience of language teachers, where teachers do not successfully use 
English in classroom communicative situations. The incomplete mastery of the target language can be provoking and lead to communication apprehension (Gregersen and Horwitz, 2002). Likewise, the lack of confidence in English knowledge can make learners uncomfortable (Williams and Andrade, 2008). The lack of confidence also leaves teachers doubting their ability to succeed, making them hesitant to use English. Murdoch states a similar opinion (2003, "a teacher's confidence was most dependent on his or her degree of language competence" (p. 258). Moreover, Murray (2006) mentions that self-confidence is a firm belief. If a person is convinced of something, he/she is not worried about the outcome, as he/she simply takes it for granted that it will go well. Thus, self-confidence is a belief that someone has in his/her ability to succeed in a task, based on whether he/she was able to do that task in the past.

As the findings obtained from the study show, lack of confidence about English knowledge occupies an important place in the reasons for linguistic insecurity-a remarkable share, as both participants indicated that not being confident in their English knowledge put them in a terrible situation. They spent much time searching and preparing the lesson. Moreover, both participants also mentioned another situation that they cannot express their ideas in English. A similar opinion is stated by Bretegnier \& Ledegen (2002) that this feeling of insecurity tends to be relevant to a perception that one's accent, choice of words, and grammar fail to align with standardized language norms, leading to the fear of being discredited and deprived of identity as members of the community. Furthermore, both participants mentioned that lack of confidence in English knowledge made them believe that they could not teach English as efficiently as native English-speaking teachers. From this mentioned, it is opposed to the previous study conducted by Lee et al. I. (2017) revealed that the participants possessed positive self-perceptions about themselves. They also perceived their strengths and weaknesses as non-native English-speaking teachers and believed they could teach English as efficiently as native English-speaking teachers.

\section{Poor Performance in English Language Teaching}

During the semi-interviews, the participants mentioned that another influence of linguistic insecurity was poor performance in their English language teaching. As teachers, the participants are demanded to be a suitable model to provide knowledge and give explicit instruction. However, the participants stated that linguistic insecurity hampered their ability to teach. Furthermore, they stated that linguistic insecurity also disturbed them most when speaking in front of students. Therefore, poor performance in English language teaching is another theme that emerges from the content analysis. Furthermore, the possibility of mispronouncing a word seems to provoke anxiety in teachers as well. To support this claim, the data collected from the research instruments are shown below:

"My serious problem in language teaching is pronunciation. I am concerned about my accent. When I am teaching, the feeling of insecurity affects my pronunciation teaching regarding my poor pronunciation. I was not confident to give my student an example to pronounce the word. I often use the online dictionary to show my students how to pronounce the words. One day, while teaching, I mispronounced the word 'promise' as 'promaI,' and one student immediately corrected me by saying 'I think this word should be pronounced as "promis." I cannot answer the questions raised by students. Sometimes, I admit to my students honestly and tell them that I will check after class and let them know in the next class. Another situation that shows my poor performance in English language teaching occurred while I was teaching grammar lessons for a special English program. One student asked me to tell the class what is the difference between and how to use 'who' and 'whom' correctly in the sentence. At that moment, I am a bit insecure because I did not know the difference between 'who' and 'whom.' Then I told the class that I will print out and distribute the sheet of this topic rule next time."

(Teacher A)

"Due to my linguistic insecurity, I was not confident to show my students how to pronounce each word. I am often concerned about my accent because some of my co-working teachers told me that I speak English with a Thai accent. When I made a mistake, some students picked me up by saying, 'Teacher, could you please pronounce it again? I think you are wrong in pronouncing that word.' This situation increases the sense of linguistic insecurity. I felt like my students looked down on me because of this situation. Last semester, I remember I tried to give my student the example of how to pronounce the words 'will' in a short form: she'll, I'll, We'll, and so forth. I could not give a clear example, and then my students asked me to clarify the correct pronunciation. It was difficult to understand in terms of intonations. Another situation to confirm my claim is when my students asked me to give examples of the grammar rules that I had taught them. I was blank for a minute and said, 'let me think.' I prefer to use other media to help me explain the lesson to conceal my linguistic insecurity."

(Teacher B)

According to the interview excerpts above, all participants mentioned that they could not perform the teaching well as expected due to linguistic insecurity. Furthermore, the participants revealed that linguistic insecurity also obstructs their English language teaching as they have to use other media such as an online dictionary and YouTube to help them explain the lesson during the class. The interview results yielded an interesting finding that teachers' linguistic insecurity can influence teaching performance as the participants are always concerned about maintaining a correct and fluent accent. In this regard, this may be one of the 
first studies investigating the effect of linguistic insecurity on EFL teachers' teaching performance, as the researcher could not find any similar studies in the literature dealing with EFL teachers' teaching experience. Apart from the effect of linguistic insecurity leading to participants' poor performance in English language teaching, the interviews also revealed that the participants' feelings of insecurity as well as other anxieties, including fear of making mistakes and having a bad accent, can lead to linguistic insecurity to develop into foreign language anxiety.

\section{Negative Self-concept}

Negative self-concept toward using the English language was another effect of linguistic insecurity that led to more unsatisfactory teaching performance. During the data collection process, the participants reported they have a negative selfconcept regarding their abilities to use English and their abilities in teaching English. The participants also added that their negative self-concept has occurred since they noted that they as a teacher have linguistic insecurity. As a result, it sometimes reduced their teaching performance below their expectations. Additionally, the theme of negative self-concept was clearly explained in the following interview excerpts:

"I feel like my English skills are inadequate. I often compare myself with other teachers. I think that other teachers have good English skills and perfect teaching performance. The most serious concern is my thought that my English teaching is insufficient as I cannot perform well in English teaching class. I am incapable of giving clear instructions to my students by using English only. I was concerned about my accent, my grammar knowledge, and my vocabulary knowledge. I cannot give my students examples to pronounce the word because I realize that my accent is terrible, and it is not even similar to the native accent. I prefer to use both Thai and English in the teaching process, even if the course requires teachers to interact with students in English only. I do not trust my skills. Sometimes, even if well-prepared for the in-detail lesson step by step, I can still not perform an impressive lesson. In other words, I am incapable of making my students understand the lesson."

(Teacher A)

"I sometimes thought that my English teaching skills are not good enough. I am often awestruck when I realize that I forget to preview the lesson. I always had the feeling of linguistic insecurity before and during the class. I honestly say that I am an unqualified English teacher. I am not sure about my skills, even if I am familiar with each English lesson. I spent much time preparing each lesson. I am unable to teach without preparing the lesson. Last month, one of my students asked me to check her self-introduction script for a university interview, and I immediately told the student to get the feedback the next day. Even if it is a short and simple script, I cannot give feedback instantly. I have to check it in-depth. Sometimes, I think that my English ability is inadequate. It can be said that I cannot teach or use it without thorough preparation."

(Teacher B)

From what the participants say in the extracts above, although the interview excerpts exposed that the participant of this study has a negative self-concept on the abilities to use English and the abilities to teach English. The participants also mentioned that their negative self-concept directly affects their teaching performance. This opinion is consistent with the studies conducted by Tonelson (1981), Burns (1982), and Tabassum (2014). These studies showed that teachers' positive self-concept contributes significantly toward their teaching performance as well as their students' achievement in learning. Both participants also indicated uneasiness about their abilities in teaching English led to decreased confidence in using English and significant anxiety.

Both participants also indicated uneasiness about their abilities in teaching English led to decreased confidence in using English and significant anxiety. A similar opinion is stated by Wernicke (2017) that linguistic insecurity impacts teachers' instructional practices and decisions to access certain kinds of professional development, and it reproduces traditional monolingual models of language learning and use, notably for students who may themselves be aspiring to become English teachers in the future. In addition, it is also similar to the opinion of Bucci and Baxter (1984) that linguistic insecurity is the speakers' negative selfperception concerning the speech variety. For example, it might happen when the speakers compare their phonetic and syntactic characteristics of speech with characteristics of an expected accurate form of the spoken language.

\section{Conclusion}

Based on the research findings discussed, the researcher is able to conclude that the present study attempted to propose the influences of linguistic insecurity on teachers' teaching performance. This present study provided understandings of Thai EFL teachers' linguistic insecurity through the perception of the Thai EFL teachers in the northeastern part of Thailand. It is welldefined that linguistic insecurity exists and is perceived by Thai EFL teachers. Therefore, the purpose of the present research study was to investigate the influence of linguistic insecurity on their teaching performance. The results from the data collection procedure revealed three influences of linguistic insecurity on Thai EFL teachers' teaching performance: lack of confidence about English knowledge, poor performance in English language teaching, and negative self-concept toward their English ability. 
Linguistic insecurity has been found to have negative effects on the well-being of the teachers and the quality of instruction inside the foreign language classroom. All research participants acknowledged that they feel insecure while speaking English in class. The participants even expressed that they feel unprofessional when they believe they cannot speak English well and maintained that they try to skip situations that show their incapability in English. The understanding of Thai EFL teachers' linguistic insecurity gained from the present study can be used as a guideline to decrease the feeling and the effects of linguistic insecurity on teachers' teaching performance when speaking. Language teachers must be aware of linguistic insecurity's existence. As presented in this study, the semi-structured interviews and classroom observation provided valuable insights from Thai EFL teachers' perspectives based on their teaching experience and their use of English in authentic communicative situations. To confirm the results, this research should be replicated with more teachers at different secondary schools and different educational levels in various academic disciplines. This study focused on investigating the influences of Thai EFL teachers' linguistic insecurity on teaching performance. Further research should also take account of other aspects such as the influences of linguistic insecurity on English skills. In addition, research on the effects of linguistic insecurity among Thai EFL teachers and strategies to cope with linguistic insecurity would be interesting. Studies on Thai EFL teachers' linguistic insecurity are needed to raise awareness and gain further insight into EFL teachers' linguistic insecurity. Moreover, in order to get a deeper understanding of teachers' linguistic insecurity and assess classroom issues and teaching realities that cannot be identified through direct research observation, teachers' diaries should be added as a research methodology.

Funding: This research received no external funding. This article was fully sponsored by the author.

Acknowledgments: The completion of this study is one of the great events I feel proud of. It should be attributed not only to my hard work in the past two years but also to the help and care I have got from a number of people. I would like to express my heartfelt gratitude to those great people. First of all, I would like to express my sincere gratitude and appreciation to my thesis advisor, Dr. Pilanut Phusawisot, for her guidance, understanding, and invaluable advice during my graduate studies. With her rich experience in research and great wisdom, she has helped me complete this study step by step. Without her willing and generous help, I would have never succeeded in the completion of this study. Certainly, my heartfelt gratitude goes to my family for their unconditional love, support, and concern about my well-being as I sought my achievement. They are the largest motivation on my way to the completion of the study. Without their love and support, this study would not have been possible.

Conflicts of Interest: The authors declare no conflict of interest.

\section{References}

[1] Aslrasouli, M., \& Vahid, M. S. P. (2014). An investigation of teaching anxiety among novice and experienced Iranian EFL teachers across gender. Procedia-Social and Behavioral Sciences, 98, 304-313

[2] Bekleyen, N. (2004). Foreign language anxiety. Çukurova Üniversitesi Sosyal Bilimler Enstitüsü Dergisi, 13(2), 27-39.

[3] Bucci, W., \& Baxter, M. (1984). Problems in linguistic insecurity in multicultural speech contexts. Annals of the New York Academy of Sciences, 433, 185-200. Retrieved from https://doi.org/10.1111/j.1749-6632.1984.tb14767.x

[4] Cheng, Y. (2002). Factors associated with foreign language writing anxiety. Foreign Language Annals, 35(6), 647-656.

[5] Cheng, Y., Horwitz, E., \& Schallert, D. (1999). Language anxiety: Differentiating writing and speaking components. Language Learning, 49, $417-446$.

[6] Cho, J. (2015). Sleepless in Seoul: Neoliberalism, English fever, and linguistic insecurity among Korean interpreters. Multilingual, 34(5), 687710.

[7] Cubukcu, F. (2007). Foreign Language Anxiety. Iranian Journal of Language Studies, 1(2), 133-142.

[8] Daftari, G. E. (2016). A study of linguistic insecurity among Turkish teachers of English. International Journal of English Language Education, $4(2), 117-130$.

[9] Goshi, M. (2005). Foreign Language classroom Anxiety: How Should the Classroom Teacher Deal with it? Journal of the School of Marine Science and Technology, 3(2), 61-66.

[10] Horwitz, M. B, Horwitz, E. K., \& Cope, J. A. (1986). Foreign language classroom anxiety. Modern Language Journal, 70(2), 125-132.

[11] Labov, W. (1966). The social stratification of English in New York City. Washington D.C.: Center for Applied Linguistics.

[12] Labov, W. (1990). The intersection of sex and social class in the course of linguistic change. Language Variation and Change, 2(2), 205-254. Retrieved from doi:10.1017/\$0954394500000338

[13] Liu, M. (2007). Anxiety in oral English classrooms: A case study in China. Indonesian Journal of English Language Teaching, 3(1), 119-137.

[14] Liu, M. (2009). Reticence and anxiety in oral English lessons. Bern: Peter Lang.

[15] Lynch, A. (2008). The linguistic similarities of Spanish heritage and second language learners. Foreign Language Annals, 41(2), 252-381.

[16] Marwan, A. (2007). Investigating students' foreign language anxiety. Malaysian Journal of ELT Research, 3, 37-55.

[17] Matsuda, S., \& Gobel, P. (2001). Quiet apprehension: Reading and classroom anxieties. JALT Journal, 23, 227-247.

[18] Medgyes, P. (1994). The Non-Native Teacher. London: Macmillan.

[19] $\mathrm{Na}$, Z. (2007). A Study of High School Students' English Learning Anxiety. Iranian EFL Journal, 9(3), 22-34.

[20] Owens, T. W., \& Baker, P. M. (1984). Linguistic insecurity in Winnipeg: Validation of a Canadian index of linguistic insecurity. Language in Society, 13(3), 337-350. Retrieved from https://doi.org/10.1017/\$0047404500010538

[21] Öztürk, G. (2012). Foreign language speaking anxiety and learner motivation: A case study at a Turkish state university (Unpublished master's thesis). Middle East Technical University, Turkey. 
[22] Öztürk, G., \& Gürbüz, N. (2013). The impact of gender on foreign language speaking anxiety and motivation. Procedia-Social and Behavioral Sciences, 70, 654-665.

[23] Pappamihiel, N. E. (2002). English as a second language students and English language anxiety: Issues in the mainstream classroom. Proquest Education Journal, 36(3), 327-355.

[24] Preston, D. R. (2013). Linguistic insecurity forty years later. Journal of English Linguistics, 41(4), 304-331.

[25] Tum, D. O. (2012). Feelings of language anxiety amongst non-native student teachers. Procedia Social and Behavioral Sciences, 47, 20552059.

[26] Young, D. J. (1992). Language anxiety from the foreign language specialist's perspective: Interviews with Krashen, Omaggio Hadley, Terrell, and Rardin. Foreign Language Annals, 25(2), 157-172. 